\title{
Aspek Religi Pada Masa Pemerintahan Raja Ugrasena (Kajian Epigrafi)
}

\author{
Made Wicakshana Essa Putra ${ }^{1 *}$, I Gst Ngr Tara Wiguna ${ }^{2}$, Ida Bagus Sapta Jaya ${ }^{3}$ \\ Prodi Arkeologi, Fakultas Ilmu Budaya, Unud \\ ${ }^{1}$ [wicakshaessa@gmail.com] ${ }^{2}$ [arkeologi_unud@yahoo.co.id] \\ ${ }^{3}$ [bagus_sapta@yahoo.com] \\ *Corresponding Author
}

\begin{abstract}
Abstrak
Religi merupakan bagian penting dari kehidupan manusia, karena Religi mengambil peran penting dalam keberadaan di dalam masyarakat atau komunitas sosial. Segala aspek religi yang termuat di dalam prasasti memiliki peranan penting pada pemerintahan Raja Ugrasena. Masalah yang dibahas dalam penelitian ini yaitu aspek religi apa saja yang termuat dalam prasasti masa pemerintahan Raja Ugrasena dan terkait peran religi terhadap kehidupan sosial masyarakat pada masa pemerintahan Raja Ugrasena. Metode pengumpulan data yang digunakan adalah studi pustaka, observasi, dan wawancara. Pada tahapan selanjutnya diolah dengan menggunakan analisis kualitatif, analisis kontekstual dan analisis etnoarkeologi. Teori yang digunakan dijadikan dasar acuan dalam penelitian ini adalah adalah teori religi, teori ritus dan teori fungsional struktural untuk mengetahui peranan religi terhadap kehidupan sosial masyarakat pada masa pemerintahan Raja Ugrasena. Hasil yang diperoleh yaitu, aspek religi yang termuat dalam prasasti masa pemerintahan Raja Ugrasena antara lain yaitu kepercayaan berupa kemunculan masa awal sekte-sekte di Bali Kuno, upacara keagamaan, bangunan suci, sarana upacara dan upacara, serta tokoh keagamaan pada awal masa Bali Kuno. Peranan religi terhadap kehidupan sosial kemasyarakat pada masa pemerintahan Raja Ugrasena yaitu religi berperan dalam interaksi sosial masyarakat di anataranya religi berperan sebagai dasar acuan dalam kehidupan masyarakat dan religi juga berperan dalam legitimasi kekuasaan pemerintahan Raja Ugrasena.
\end{abstract}

Kata Kunci : Peranan, Religi, Pemerintahan, Raja Ugrasena.

\begin{abstract}
Religion is an important part of human life, because it is considered to have meaning in life. Because it takes an important role in the existence of society and social community. All aspect of religion contained in the inscription have an important role in the reign of the king Ugrasena. The problem discussed in this research was what are the aspects of religion that contained in the inscription during the reign of the king Ugrasena and related to the religious impact to the social life of society during the reign of the King Ugrasena This research used some method of collecting data, analyzing the data, and theory to solve the problem. The method of collecting data that used were observation, literature review, and interview. The next step, the data were procesed by using qualitative analysis, contextual analysis and analysis etnoarchaeology. The theories that used as the basic theory in this research is the theory of religion, ritual theory and fungsional structural theory to determine the role of religion to social life of the society during the reign of King Ugrasena. The results of this study found that the religious aspects, which were contained in inscriptions during the reign of King Ugrasena that there were the begining of the sects in ancient Bali, religious ceremony, sacred building, the tools of religious ceremony, as well as the religious figures in the erly days of ancient Bali. The role of religion to the social life of the society in the reign of the King Ugrasena showed that religion had a role in the society social interaction such as the basis of reference in the society, and also play a role as the legitimation of the power of King Ugrasena Kingdom
\end{abstract}

Keywords: Role, Religion, Reign, King Ugrasena. 


\section{Latar Belakang}

Kehidupan religi dan adat istiadat masyarakat Bali Kuno ternyata sepertinya masih melanjutkan tradisi prasejarah yaitu dari masa perundagian, yang kemudian dilanjutkan dengan kebudayaan Hindu-Budha di Bali sehingga membuat kebudayaan menjadi semakin berkembang dan kompleks. Sifat religius juga mempengaruhi eksistensi religi patut diakui mengakar kuat pada kehidupan dari masyarakat Bali yang dicerminkan di dalam bangunan suci (pura), administrasi desa, dan berbagai kegiatan upacara keagamaan (Goris, 1974: 25). Hal tersebut terjadi karena kebudayaan yang terdiri dari sistem, nilai dan norma selalu dijiwai oleh kekuatan religi, sehingga dapat dikatakan bahwa spirit religi merupakan akar kebudayaan Bali.

Masyarakat pada masa Bali Kuno sangat memperhatikan kehidupan religi. Hal itu terlihat dari sejumlah bangunan pemujaan yang sering disebutkan dalam prasasti. Seperti Hyang Api, Hyang Tanda, Hyang Tahununi, Hyang Karimama dan banguněn pertapaan yang dibangun sebagai bukti suburnya kehidupan keagamaan pada masa Bali Kuno. Apabila diperhatikan dari penemuan jejak keagamaan berupa materai-materai tanah liat dalam stupika dan fragmen prasasti batu yang ditemukan di daerah Pejeng, Kabupaten Gianyar (dari abad IX), menunjukan adanya pengaruh agama Hindu dan Buddha untuk pertama kalinya di daerah Bali (Wardi, 1986: 1-3). Selain itu, ditemukannya prasasti-prasasti bertipe Yumu Pakatahu yang diawali dengan prasasti Sukawana AI berangka tahun 804 Śaka, dilanjutkan dengan prasastiprasasti yang di keluarkan oleh Raja Ugrasena yang sudah menunjukkan adanya kegiatan keagamaan, dan nama tokoh keagamaan hal ini diketahui dari beberapa istilah antara lain Bhikṣu Śiwakangsita, Śiwa Nirmmala, Śiwa Prajñ̃ Bhikșu Ciwarudra, Bhikșu Anantasukma, Bhikșu Prabawa, Bhikșu Dharmmaswara, Bhikșu Padmadewa, Bhikșu Sabha, dan Bhikșu Widyateja. Selain bangunan dan tokoh keagamaan dalam prasasti-prasasti Raja Ugrasena juga ditemukan sajian dalam upacara yang dilakukan oleh masyarakat masa Bali Kuno. Dalam peralatan atau sarana ritus dan upacara dikenal caru, marhantwang, parwuruktanahan, kajang dan beberapa sarana pemujaan lainnya (Ardika, 1983: 54-55).

Penelitian ini difokuskan pada prasasti yang diterbitkan oleh Raja Ugrasena. Prasasti-prasasti tersebut memuat perhatian Raja Ugrasena terhadap kegiatan religi serta kesejahteraan masyarakat pada masa itu. Hal ini dibuktikan dengan adanya pembuatan bangunan suci Hyang Api sebagai sarana pemujaan terhadap nenek moyang. Selain itu, berdasarkan temuan prasasti pada masa pemerintahan Raja Ugrasena maupun sebelumnya banyak aktivitas yang dapat dikaitkan dengan aspek-aspek religi pada kehidupan masyarakat Bali Kuno.

Berdasarkan penjelasan tersebut maka perlu untuk dilakukan penelitian mengenai "Aspek Religi Pada Masa Penerintahan Raja Ugrasena (Kajian Epigrafi)".

\section{Pokok permasalahan}

Berdasarkan uraian telah di paparkan dalam latar belakang, maka terdapat dua permasalahan yang dijadikan fokus dalam penelitian ini yaitu sebagai berikut.

1. Aspek religi apa saja yang terdapat di dalam kehidupan masyarakat pada masa pemerintahan Raja Ugrasena 
2. Bagaimana peran religi terhadap kehidupan sosial masyarakat pada pemerintahan Raja Ugrasena

\section{Tujuan Penelitian}

Tujuan penelitian ini yaitu: 1) Untuk mengetahui aspek-aspek religi yang berlangsung pada kehidupan masyarakat Bali Kuno berdasarkan prasasti masa pemerintahan Raja Ugrasena dan ssebelumny. 2) Untuk mengetahui peran religi terhadap kehidupan sosial kemasyarakatan pada masa pemerintahan Raja Ugrasena yang termuat di dalam prasasti.

\section{Metode Penelitian}

Penelitian ini menggunakan pendekatan yang bersifat kualitatif. Riset yang digunakan pada pendekatan kualitatif bersifat deskriptif dan cenderung menggunakan analisis dengan pendekatan induktif. Metode kualitatif lebih menekankan pada analisisnya pada proses penyimpanan induktif serta pada analisis terhadap dinamika hubungan antarfenomena yang diamati dengan menggunakan logika ilmiah (Wiratha, 2005:134). Penelitian ini menggunakan Prasasti pada masa Pemerintahan Raja Ugrasena sebagai data primer.

Teknik pengumpulan data yang digunakan dalam penelitian ini yaitu: Studi pustaka, observasi, dan wawancara yang mendalam dari masyarakat di lokasi penelitian yaitu daerah Desa Desa Kelusa Payangan, Gianyar.

Analisis yang dilakukan dalam penelitian ini yaitu analisis kualitatif untuk mengguraikan data dalam bentuk deskriptif yaitu menganalisis istilah aspek-aspek religi yang terdapat di dalam beberapa prasasti Raja Ugrasena. Analisis selanjutnya yaitu Analisis kontekstual yang digunaka untuk untuk menentukan bagaimana menangani hubungan satu teks prasasti pada masa pemerintahan Raja Ugrasena dengan teks prasasti yang terdahulu yaitu prasasti yang bertipe Yumu Pakatahu yang memiliki karakter yang sama. Analisis lainnya yaitu Analisis Etnoarkeologi yaitu digunakan untuk menganalogikan status dan fungsi pemujaan terhadap bangunan suci yang disebutkan di dalam prasasti pada masa kini dengan status dan fungsi bangunan suci pada masa lalu.

\section{Hasil dan Pembahasan}

Masyarakat pada masa Bali Kuno sangat memperhatikan kehidupan religi. Hal itu terlihat dari sejumlah bangunan pemujaan yang sering disebutkan dalam prasasti. Seperti Hyang Api, Hyang Tanda, Hyang Tahununi, Hyang Karimama dan banguněn pertapaan yang dibangun sebagai bukti suburnya kehidupan keagamaan pada masa Bali Kuno. Salah satunya pada masa pemerintahan Raja Ugrasena yang sangat memperhatikan kehidupan religinya.

\subsection{Kehidupan Religi pada Masa Pemerintahan Raja Ugrasena.}

Ada empat hal penting yang dapat memberikan gambaran umum tentang kehidupan religi pada masa Bali Kuno yakni : 1) sistem kepercayaan pada masyarakat Bali Kuno yang disebut juga dengan sekte, 2) upacara keagamaan, 3) sarana upacara dan bangunan suci, dan 4) umat dan tokoh keagamaan. Kehidupan Religi tersebut akan dibahas di bawah ini.

\section{Sistem kepercayaan (Sekte)}

Sistem kepercayaan adalah gagasan manusia yang menyangkut kepercayaan dan konsepsi manusia tentang sifat-sifat tuhan, mengenai kebenaran tertinggi, tentang terjadinya alam dan dunia, tentang wujud dan ciri-ciri kekuatan sakti, roh nenek moyang dewa-dewa serta mahluk halus lainya. Menurut Goris setelah abad IX atau X Masehi jumlah sekte di Bali semakin bertambah, dan kelompok ulama semakin terbagi dalam beberapa sekte. Goris memperkirakan 
bahwa di Bali pada masa lampau pernah berkembang Sembilan sekte yaitu (1) Śiwa-Siddhanta, (2) Pāśspata, Bhairawa, (4) Wiṣnawa, (5) Boddha atau Sogata, (6) Brāhmana, (7) Rṣi, (8) Sora, dan (9) Ganapatya (Goris, 1974: 11-12).

Data prasasti menunjukan berdasarkan sekte-sekte tersebut hanya beberapa sekte yang mempunyai pengaruh yang sangat kuat di dalam kehidupan masayarakat Bali Kuno. Dikatakan bahwa pengaruh sekte Siwa Siddhānta dan Budhha Mahayana mempunyai pengaruh yang cukup kuat diantara sekte lainya. Oleh karena itu agama yang berkembang pada zaman Raja Ugrasena adalah agama Hindhu dengan aliran Śiwa dan agama Budha dengan aliran Mahāyana. Pada masa pemerintahan Raja Ugrasena diperkirakan sudah berkembang sekte Wiṣnawa. Nampaknya Agama pada masa Bali Kuno telah difungsikan secara baik dan benar sehingga keberagaman sekte tidak menjadi hambatan dalam upaya membina kerukunan hidup warga kerajaan (Astra, 2009: 24-39).

\section{Upacara Keagamaan}

Aktivitas upacara adalah tindakan manusia dalam melaksanakan kabaktiannya terhadap tuhan, dewadewa, dan roh nenek moyang, dalam usaha untuk berkomunikasi dengan tuhan. Upacara keagamaan merupakan wujud nyata dari praktek religi suatu masyarakat dan merupakan suatu aktivitas yang penting. Berdasarkan prasasti masa Ugrasena terdapat jenis upacara keagamaan yang berdasarkan data prasasti, yaitu Daiwakarmmana, Marhantuwang, Pavuruktahanan, dan Caru. Seperti yang termuat dalam prasasti Dausa, Pura Bukit Indrakila AI yang memuat adanya upacara Daiwakarmmana.

Lembar Ib
2. bhikșu grama, musirang ya marumaḥ ditu, kobhayadharmman ya pamasamahyan pahlaryan di sattra di hyangāpi, di ruang ditu, psua

1. nga air, sarang, pulu, paryuk, tikar, di anak marakta ditu, mai pasanghulanya daiwakārmma (Goris, 1954: 69).

Artinya:

Lembar Ib

2. Bhikṣu kawin, mengungsi dan bertempat tinggal disana, kewajibannya adalah melengkapi bangunan di pesanggrahan di kuil Hyang Api, di ruang disana.

1. mereka mengeluarkan air, kukusan nasi, tempat beras, periuk, tikar bagi mereka yang tinggal disana, dan melakukan kegiatan pemujaan untuk dewa (Ardika dan Beratha, 1998: 9091).

\section{Sarana Upacara dan Bangunan Suci}

Sarana upacara yang digunakan dalam masyarakat Bali Kuno seperti bunga, buah-buahan, umbi-umbian, binatang-binatang dan benda benda lainya. Dalam masyarakat Bali masa kini, terdapat sesajen atau banten yang digunakan sebagai sarana atau media pemujaan yang memiliki arti simbolisdan makna filosofi, salain itu terdapat juga media-media lainnya yang memiliki makna filosofis (Hartawan, 2011: 48-51). Hal ini juga terdapat pada masa pemerintahan Raja Ugrasena, yang menggunakan media sesajen berupa makanan dan benda-benda lainya seperti kajang, air, api, janur (danur), tikar dan benda lainya untuk media dalam melaksanakan pemujaan atau upacara keagamaan seperti yang termuat dalam prasasti Dausa Pura Bukit Indrakila AI.

Lembar Ib

6. bhikșu grama, musirang ya marumah ditu, kobhayadharmman ya 
pamasamahyan pahlaryan di sattra di hyangāpi, di ruang ditu, psua

lembar IIa

1. nga air, sarang, pulu, paryuk, tikar, di anak marakta ditu, mai pasanghulanya daiwakārmma, manundun pamudri (Goris, 1954: 69).

Artinya

Lembar Ib

6. apabila ada Bhikṣu kawin, mengungsi dan bertempat tinggal disana, kewajibannya adalah melengkapi bangunan di pesanggrahan di kuil Hyang Api, di ruang disana.

Lembar IIa

1. mereka mengeluarkan air, kukusan nasi, tempat beras, periuk, tikar bagi mereka yang tinggal disana, dan melakukan kegiatan pemujaan untuk dewa, membangunkan pamudri (Ardika dan Beratha, 1998: 90-91 ).

Sarana upacara lainnya yang termuat dalam prasasti Raja Ugrasena yang dapat diamati penulis antara lain yaitu Kajang dan donũr. Kajang dalam prasasti Pengotan AI yang di keluarkan oleh Raja Ugrasena adalah yang dimaksud dengan rurub kajang. Maka penulis dapat asumsikan bahwa kajang tersebut merupakan sarana upacara yang wajib dipenuhi dalam upacara pitra yadnya. Mangjahit kajang yang disebutkan dalam prasasti Ugrasena itu dapat diartikan membuat rurub kajang. Sedangkan Donür istilah ini ditemukan dalam kutipan prasasti Bangli Pura Kehen AI. doñur yang diartikan sebagai daun atau janur kelapa.

Bangunan suci merupakan media berupa tempat dan bangunan yang digunakan untuk melakukan pemujaan terhapat Tuhan, para dewa dan roh para leluhur, khususnya masyarakat Bali yang beragama Hindu yang biasanya disebut dengan pura atau candi. Selain itu, masyarakat pada masa Bali Kuno juga menggunakan candi sebagai tempat pemujaan dan juga sebagai tempat pendharmaan roh leluhur yang sudah mangkat. Dalam pembangunan sebuah bangunan suci pada umumnya memiliki aturan-aturan tertentu sesuai dengan ajaran atau pedoman yang digunakan masyarakat pemilik bangunan suci tersebut.

Berdasarkan data prasasti, terdapat beberapa nama serta jenis bangunan suci pada masa pemerintahan Raja Ugrasena diantaranya Hyang Api, Hyang Wihara, Hyang Padmaka, Silunglung, Sala, Meru, Hyang Tanda, Hyang Karimama, Hyang Tahununi, Partapanan, Punta Hyang, Bhatara Da Tonta, dan Sang Hyang Di Trunyan.

\section{Umat dan Tokoh Agama}

Umat agama adalah kesatuan sosial yang menganut keyakinan dan yang melaksanakan ritus serta upacara agama yang bersangkutan. Data prsasasti Raja Ugrasena dan sebelum raja Ugrasena sudah menunjukan adanya tokoh keagamaan hal ini diketahui dari beberapa istilah diantaranya Bhikșu Siwa-kangsita, Śiwa Nirmala, Śiwa Prajnã, Bhikșu Śiwarudra, Bhikșu Anantasukma, Bhikșu Prabawa, Bhikșu Dharmmaswara, Bhikșu Dharmmacchaya, Bhikșu Padmadewa, Bhikșu Sabha dan Bhikșu widjateja. Dari istilah tersebut nampaknya menunjukan ada dua pendeta yang selalu disebutkan dalam prasasti maupun dalam jabatan tingkat pusat yaitu pendeta Śiwa dan pendeta Buddha. Pendeta Śiwa dan pendeta Buddha yang namanya termuat dalam tiap prasasti tidak selalu sama antara prasasti satu dengan lainnya. Hal tersebut terjadi karena tidak semua prasasti menyebutkan tempat yang sama yang menjadi daerah seorang pejabat keagamaan bertugas. Setiap pejabat keagamaan mempunyai daerah kekuasaan berbeda-beda. Berdasarkan data prasasti jelas menggambarkan bahwa Raja Ugrasena melakukan 
perjalanan dan memberikan anugerah kepada Pitāmaha di Buwunan dan Pitāmaha di Songan, tercermin pada kutipan prasasti Babahan I No. 102.

Lembar I

1. ..., tatkālan sang ratu $\dot{S} r-I$ ugrasena, tua lumaku ka buwunan, saha twa yanugrahenda tua da pitāmaha

2. Di buwunan, ida Bhikṣu dharmmesiwara, me da pitāmaha di songan, Bhikșu dharmmacchāya, me partapanan dahulun bukit ptung, saha twa pisukatang sang ratu $\dot{s} r-I$ ugrasena (Goris, 1954: 64).

Artinya:

Lembar I

1. ..., tatkala Sang Ratu Sri Ugrasena melakukan perjalanan ke Buwunan dan memberikan anugerah kepada beliau Pitamaha

2. di Buwunan yang bermana Ida Bhikṣu Darmmeswara dan beliau Pitamaha di Songan bernama Bhikșu Drahmmacchaya, serta pertapaan Dahulun Bukit di Ptung. Yang diukur oleh Sang Ratu Sri Ugrasena (Ardika dan Beratha, 1998: 76-77).

\subsection{Peran Religi Terhadap Kehidupan Sosial Masyarakat Pada Pemerintahan Raja Ugrasena. \\ 1. Peran Religi Dalam Interaksi Sosial Masyarakat}

Dalam menjalani kehidupan di dunia religi memiliki fungsi dan peran yang sangat penting. Religi mengambil peran penting di dalam masyarakat atau komunitas sosial, karena suatu kepercayaan atau agama akan tetap ada jika terus diamalkan oleh masyarakat secara berlanjut. Dalam masyarakat religi menjadi salah satu faktor penunjang kehidupan terutama dalam kehidupan spiritual. terkait nilai dan norma yang menjadi kesepakan bersama.

Peranan religi selanjutnya dalam kehidupan masyarakat adalah sebagai sistem pemersatu masyarakat. Dimana religi berperan sebagai wadah untuk masyarakat berkumpul dan melakukan kegiatan sosial (Amran, 2015 29-30). Masyarakat pada masa pemerintahan Raja Ugrasena juga menunjukan adanya suatu kegiatan yang mempersatukan masyarakat dalam satu wadah kegiatan keagamaan, dalam hal ini masyarakat berkumpul untuk melakukan kegiatan upacara keagamaan.

Peran religi yang lainnya yaitu sebagai kontrol sosial, ajaran agama oleh penganutnya dianggap sebagai norma sehingga religi berfungsi sebagai pengawasan sosial secara individu maupun kelompok karena agama secara instansi, merupakan norma bagi pengikutnya.

Religi sebagai kontrol sosial yang dimaksud adalah menjaga harmonisasi sosial antar masyarakat agar tidak runtuh oleh perilaku-perilaku menyimpang yang dilakukan oleh masyarakat dengan cara panduan moral, hukum dan sanksi. Religi ikut bertanggung jawab atas keseimbangan kehidupan manusia. Religi membawa noma-norma universal yang mampu memilah kaidah-kaidah susila yang baik dan menolak kaidah yang tabu dan terlarang. Religi memberikan pengawasan kepada masyarakat dengan ajaran-ajaran yang telah disepakati agar tetap ada pada rel yang seharusnya. Selain itu religi juga memiliki kekuatan untuk memberi sanksi yang harus dijatuhkan kepada masyarakat yang melakukan kesalahan dan melanggar aturan yang telah disahkan dalam sebuah peraturan di masyarakat.

Masyarakat Bali Kuno sangat memegang teguh aturan yang diberikan oleh raja. Seorang raja sering mengeluarkan suatu dekrit atau undangundang (peraturan) yang ditulis dalam bentuk prasasti. Untuk menjamin kelanggengan undang-undang yang telah ditetapkan dalam prasasti tersebut, di dalam prasasti dilengkapi dengan 
sapatha (kutukan) sebagai sanksi yang bersifat psikologis yang ditujukan kepada meraka yang berani melanggar atau merubah aturan-aturan itu yang dapat meresahkan dan membahayakan kehidupan masyarakat (Wardi, 1991: 3840).

\section{Peran Religi Dalam Pemerintahan Raja Ugrasena.}

Peran religi dalam birokrasi masa pemerintahan Raja Ugrasena pada penelitian ini adalah religi berperan dalam upaya pelegitimasian kekuasaan Raja Ugrasena di dalam masyarakat kerajaan dan sebagai penguat kebijakan politik. Legitimasi dapat diartikan sebagai penerimaan dan pengakuan masyarakat terhadap hak moral pemimpin untuk memerintah, membuat, dan melaksanakan keputusan politik.

Upaya peligitimasian yang dilakukan Raja Ugrasena untuk memperkuat kedudukan sebagai seorang raja dilihat dari aspek religi yang digunakan yaitu melalui peran religi yang digunakan berupa upacara kegamaan dan juga pemberian hadiah bangunan suci Hyang Api kepada penduduk desa yang telah bekerja siang dan malam kepada Raja Ugrasena. Selain itu Raja Ugrasena mengutus Pitamah di Buwunan dan di Songan untuk melakukan upacara kematian terhadap masyarakat yang mati secara tidak wajar, agar tidak meninbulkan keributan di masyarakat. Cara tersebut digunakan oleh Raja Ugrasena untuk menarik simpati masyarakat, karena pada dasarnya seorang raja harus menjadi pelindung masyarakat ketika kesusahan. Pentingnya peran religi sebagai sarana legitimasi kekuasaan nampak cukup jelas pada masa Bali Kuno, salah satunya yaitu pada masa pemerintahan Raja Ugrasena. Legitimasi kekuasaan mampu memberikan kharisma tersendiri bagi seorang raja yang patut dihormati dan disegani bagaikan dewa oleh para bawahan serta rakyatnya.

Selain itu, peran religi sebagai penguat kebiajakan politik pada masa itu. Upaya tersebut terdapat dalam pemerintahan Raja Ugrasena yang dicerminkan dengan adanya kebijakan mengenai hukum tawan karang. Hukum tawan karang adalah hak datu, ratu atau raja untuk merampas perahu atau kapal yang terdampar di laut atau di muka pantai dan mengambil semua penumpang dan seluruh barang-barang muatannya. Sebabnya karena pihak luar (asing) melanggar dan melewati batas wilayah perairannya (Wardha, 1987: 2). Hukum tawan karang tersebut termuat dalam prasasti Sembiran AI yang isinya sebagai berikut.

Lembar IIIb

2. yanada twānak palamswan marhuma, mangrawi ditu, pamayarn

3. pangrama mā 1 di hadiri, me yanāda taban karang ditu, perahu, lançang jukung, takala, anak banwa katahwan di ya, kajadyan wrddhi $\operatorname{kinwā}(\tilde{n a}) m a$

4. katahu aku, pyanekangña bhaktiña di bhatāra punta hyang, cincin singhāla, bantuk 1 tanda haji (Goris, 1954 : 67).

Artinya

Lembar IIIb

2. bila ada penduduk dari luar desa(julah) mengerjakan sawah, beristri di sana agar mereka membayar

3. pungutan 1 masaka setiap orang, dan bila ada tawan karang(pajak penawanan) disana terhadap perahu, sampan, jukung, bila diketahui oleh penduduk desa maka hasil tawanannya dijadikan wrddhi(untuk kemakmuran penduduk)

4. supaya aku diberitahu. Agar mempersembahkan baktinya kepada bhatara Punta Hyang yakni sebentuk cicin Singhata dengan ciri/tanda dari 
raja, (Ardika dan Beratha, 1996 : $83)$.

Berdasarkan kutipan prasasti di atas pada masa pemerintahan Raja Ugrasena diberlakukan hukum tawan karang yaitu bila ada sampan, perahu dan sejenisnya yang terdampar di wilayah desa, penduduk berhak menawannya dan segala denda yang diperoleh menjadi milik bangunan suci (wṛ̣̂dhi) dan Punta Hyang.

\section{Simpulan}

Berdasarkan atas uraian yang telah dijelaskan pada bab-bab sebelumnya, maka pada bagian ini disampaikan beberapa simpulan.

Religi akan mempengaruhi kehidupan masyarakat itu sendiri. Aspek religi yang dapat diamati pada prasasti yang dikeluarkan oleh Raja Ugrasena meliputi sistem kepercayaan berupa sekte, beberapa jenis upacara keagamaan, bangunan suci, serta tokoh-tokoh keagamaan. dari beberapa aspek religi tersebut masih dapat diamati keberadaannya hingga masa sekarang. Misalnya sistem kepercayaan masyarakat Bali Kuno pada masa pemerintahan Raja Ugrasena terhadap kekuatan dewa-dewa Hindu masih berlangsung dan dapat diamati pada masyarakat Bali sekarang. Beberapa upacara kegamaan pada masa pemerintahan Raja Ugrasena masih dapat dijumpai contohnya penggunaan sesajen makanan yang masih dilakukan oleh masyarakat Bali. Beberapa bangunan suci yang disebutkan di dalam prasasti juga masih dapat diamati keberadaan. Seperti Hyang Api yang masih dapat dijumpai dalam kehidupan masyarakat Bali sekarang. Keberadaan tokoh keagamaan yang disebutkan dalam prasasti telah banyak mengalami perubahan dalam penyebutanya pada masa sekarang.

Aspek religi yang termuat dalam prasasti masa pemerintahan Raja Ugasena memliki peran yang penting dalam kehiduapan masyarak Bali saat itu. Dua diantaranya yaitu religi berperan sebagai interaksi sosial di dalam masyarakat dan religi berperan dalam pemerintahan Raja Ugrasena. Masyarakat menjadikan religi sebagai dasar atau acuan dalam menjalani kehidupan bermasyarakat yang baik dan tidak menyimpang dari norma-norma atau aturan yang sudah ditentukan. Peranan religi selanjutnya dalam kehidupan masyarakat adalah sebagai sistem pemersatu masyarakat dimana religi berperan sebagai wadah untuk masyarakat berkumpul dan melakukan kegiatan sosial. Selanjutnya religi sebagai kontrol sosial yang dimaksud adalah menjaga harmonisasi sosial antar masyarakat agar tidak runtuh oleh perilaku-perilaku menyimpang yang dilakukan oleh masyarakat dengan cara panduan moral, hukum dan sanksi. Religi ikut bertanggung jawab atas keseimbangan kehidupan manusia. Religi juga difungsikan sebagai sarana legitimasi oleh para penguasa, legitimasi dianggap penting bagi pemimpin pemerintahan karena legitimasi mempunyai kekuatan sehingga bisa memicu kestabilan politik dan memungkinkan terjadinya perubahan sosial dan meningkatkan kualitas kesejahteraan masyarakat.

\section{Daftar Pustaka}

Arman, Ali. 2015." Peranan Agama dalam Perubahan Sosial Masyarakat". Jurnal. Hikmah. Jakarta. Universitas Indonesia.

Ardika, I Wayan. 1983. "Masa Pemerintahan Raja Ugrasena". Laporan Penelitian Denpasar. Fakultas Sastra Universitas Udayana.

Ardika, I Wayan \& Ni Luh Sutjiati Beratha, 1996. "Perajin Pada Masa Bali Kuno Abab IXXI Masehi”. Laporan Penelitian. 
Denpasar: Fakultas Sastra, Universitas Udayana

Ardika, I Wayan \& Ni Luh Sutjiati Beratha, 1998. "Perajin Pada Masa Bali Kuno Abab IXXI Masehi”. Laporan Penelitian. Denpasar: Fakultas Sastra, Universitas Udayana.

Hartawan, I Dewa Nyoman. 2011. Uang Kepeng Cina Dalam Ritus Masyarakat Bali. Denpasar. Pustaka Larasan.

Goris, Roelof. 1954a. Prasasti Bali I. Bandung: N.V. Masa Baru.

Goris, Roelof. 1974. Sekte-Sekte di Bali. Jakarta. Bhatara.

Wardha, I W. 1987. Tawan Karang (Satu Kasus Belli di Bali). Denpasar : Jurusan Arkeologi Fakultas Sastra Universitas Udayana.

Wardi, I Nyoman. 1986. "Keagamaan pada Zaman Bali Kuno Abad XXI (Suatu Kajian Epigrafi)". Skripsi. Denpasar: Jurusan Arkeologi Fakultas Sastra Universitas Udayana .1991. "Sekilas Tentang Sapatha Dalam Prasasti Bali”. Laporan Penelitian. Denpasar. Fakultas Sastra Universitas Udayana.

Wiratha, I Made. 2005. Metodelogi Penelitian: Sosial Ekonomi. Yogyakarta: Andi Of 